\title{
The Dangers of Mindfulness: Another Myth?
}

\author{
Bhikkhu Anālayo ${ }^{1}$
}

Accepted: 26 June 2021 / Published online: 9 August 2021

(c) The Author(s) 2021

\begin{abstract}
Criticism of potential drawbacks of mindfulness is crucial for the field to move forward and remain grounded in reality rather than become carried away by the mindfulness hype. At the same time, however, such criticism needs to be reasonable and based on actual facts rather than subjective imagination. The allegation that mindfulness is intrinsically dangerous appears to have been influenced by unreasonable claims made by Daniel Ingram, which have been taken seriously due to an apparent lack of acquaintance of some scholars with Buddhist doctrine and with genuine forms of insight meditation.
\end{abstract}

Keywords Adverse effects $\cdot$ Arahant $\cdot$ Daniel Ingram $\cdot$ Insight knowledges $\cdot$ Side effects $\cdot$ Vicissitudes of meditation

The remarkable spread of mindfulness-related practices has resulted in a form of hype (Van Dam et al. 2018). In order for mindfulness research and applications to stay grounded and avoid potential pitfalls resulting from this hype, constructive criticism by academic peers is indispensable and highly welcome.

Yet, at times, such criticism can itself succumb to the hype, in the sense of going overboard and taking on a life of its own that is no longer grounded in reality. Hence, with all due recognition to the need for criticism and objections to be heard and taken seriously, some of these overstate their case to such an extent that they call for an attempt to return to the sobriety that should ideally inform research on mindfulness and meditation.

One dimension of mindfulness-based practices that has deservedly inspired criticism is the trend toward commercialization. However, the employment of the catchy phrase "McMindfulness" has led to an overstatement of such criticism by Purser (2019). An inspection of several arguments, made in support of this type of criticism, shows that these do not stand up on closer examination (Anālayo 2020b).

Bhikkhu Anālayo

1 Barre Center for Buddhist Studies, 149 Lockwood Road, Barre, MA 01005, USA

\section{The Dangers of Mindfulness}

Another in itself pertinent and deserved criticism of mindfulness practices has the important function of counterbalancing an overstating of their positive repercussions, which at times almost gives the impression that mindfulness has come to be viewed as a panacea for all possible problems. In view of the current hype, such criticism is indeed needed. It should be made clear that mindfulness is not in itself the solution for everyone under all circumstances. Someone suffering from trauma may require other types of interventions or additional practices in order to deal more efficiently with the challenges that have arisen. Hence, there is definitely a need for mindfulness practices and meditations to become increasingly more "trauma-sensitive" (Treleaven 2018).

Once 3 to $10 \%$ of patients in psychotherapies in general experience adverse effects, it only stands to reason that the same can be expected of MBCT (Mindfulness-based Cognitive Therapy) and other mindfulness-related programs (Baer et al. 2021). As noted by Baer et al. (2019, p. 111):

In well-established approaches to health and wellbeing, including psychotherapy, pharmacotherapy, and physical exercise, some participants suffer serious harm or get meaningfully worse ... Evidence-based MBPs have important commonalities with these approaches ... Because of these commonalities, it is essential to consider the possibility that some participants in evidence-based MBPs may get worse. 
For this reason, there is a pressing need to encourage those who are researching mindfulness-based programs to report adversities in published papers, in order to help develop a body of knowledge on potential drawbacks that can then inform the deployment of strategies and adjustments in order to minimize potential harm.

At the same time, however, drawing attention to potential adversities should not lead to what Vörös (2016, p. 78) has described as a possible "shift from the mythization phase, in which mindfulness is presented as panacea for all the ills and evils of contemporary society, to the demonization phase, in which it will be stigmatized as something too unpredictable and hazardous for clinical purposes." A tendency toward such a shift appears to be evident in publications that conflate mindfulness-based programs in the clinical setting with intensive insight meditation in a retreat setting and the possible experience of the so-called insight knowledges (Barford 2018; Compson 2018; Grabovac 2015). The first of these authors explicitly refers to Daniel Ingram, who thus appears to be a chief source for an overstatement of the dangers supposedly inherent in any form of mindfulness practice.

A better appreciation of the profusion of such ideas requires a close look at Daniel Ingram's main publication (2008/2018), in particular regarding his reinterpretation of the Theravāda scheme of insight knowledge, his claim to be an arahant, and his style of insight meditation as compared to the traditional practice taught by Mahāsi Sayādaw (1904-1982).

\section{A Reinterpretation of the Insight Knowledges}

The insight knowledges offer a description of the progress of insight as understood in Theravāda texts and meditation traditions. Although in themselves the result of a process of historical development (Anālayo 2012, 2019b), the finalized scheme of the insight knowledges, as described in the Visuddhimagga (translated Ñānamoli 1991), for example, has served as an authoritative reference point for Theravāda insight meditation.

Even though Ingram (2008/2018) employs the same terminology of the insight knowledges, his actual descriptions of the progress of insight involve rather substantial reinterpretations of the stages of insight. This departure from the traditional model is a new development that does not appear to have precedents in the history of Theravāda insight meditation, in the sense that personal experiences are accommodated to the map of meditative progress by adjusting the latter. In the present case, this went to the extent of identifying childhood experiences and dreams as conforming to certain insights (e.g., pp. 443-445 and 472). With all due allowance for personal freedom, it needs to be clearly recognized that such ideas no longer do justice to the intended meaning of the stages of insight in the Theravāda model (Anālayo 2020a), which are about profoundly transformative experience resulting from prolonged and intensive cultivation of insight meditation in a retreat setting.

A central factor helping to understand the dynamics of such reinterpretation appears to be a strong fascination with maps, evident in the statement in Ingram (2008/2018, p. 272): I "care incredibly much about the maps." Due to such fascination, the scheme of the insight knowledges seems to have gradually morphed into a script to be executed in meditation and applied retrospectively to previous experiences (Anālayo 2020a). Since the personal experiences described by Daniel Ingram do not fit the authoritative description of the insight knowledges adequately, this appears to have led to an ongoing process of adjusting the map to achieve a better congruence. The final result of the proposed development is that the map provided by Daniel Ingram has little in common with the original description of the progress of insight. A key element here is a tendency for deep meditative insight to become conflated with daily life situations, such as watching TV as the supposed occasion for the occurrence of the highest of the insight knowledges, "equanimity toward formations" (p. 245).

With the basic trajectory of such conflation in place, the evolving reinterpretation of the insight knowledges seems to have broadened out further to incorporate bits and pieces from various other contemplative traditions, resulting in a map subjectively believed to reflect "an innate part of human development" (p. 218). This trajectory can perhaps best be viewed as reflecting the universalization of subjectivity in an attempt to authenticate the self-made map.

Such seemingly ad hoc pursuit of elevating content and modes of first-person experience to the rank of innate and universal is quite different, for example, from psychoanalytical or comparative approaches to the phenomenology of the lived religious or contemplative experience of an individual or group. The problem here is that Daniel Ingram bases himself on a circularity between his own personal experience and an adjustment of an existing map that is subjected to rewriting to accommodate his own idiosyncratic contemplative development, being thereby stripped off its salient features and internal consistency that constitute its epistemological authoritativeness within its original context. Nevertheless, in this muted format, it is used in order to confer a seal of authority to his own experience and mapping. It is based on this procedure that Daniel Ingram posits subjective "attainments" as innate and universal phenomena. However, fact-checking of his attainment claims against the actual model (within its own context, an objective source of epistemic authority) reveals ongoing intentional manipulation of the original source. Having won a public audience who puts the created map into practice, the audience's own 
first-person experiences are then used as supportive evidence to legitimize the above-described short-circuiting.

In an invited comment on the analysis of this re-interpretation of the insight knowledges, provided in Anālayo (2020a), the internationally renowned meditation teacher Jack Kornfield (2020) offered the following assessment:

The profound insight knowledges of the Progress of Insight are not accessible and common in ordinary life, in times like just walking about or watching TV. In fact, encouraging students to claim the experience of the progress of insight in daily activities and meditation can lead the mind to construct the feeling of experiences that are much less profound than the spontaneous and powerful illuminations of the actual progress of insight. This is a danger which undercuts the profound and spontaneous transformation during the deep Progress of Insight, and is a misguided understanding against which the masters in the Mahasi tradition have regularly cautioned.

This assessment shows that the question at stake is not about asserting property rights over the Theravāda scheme of insight knowledges in an attempt to affirm religious orthodoxy. Instead, there is a need to clarify that the clinical relevance and potential of the model presented by Ingram need to be evaluated apart from considerations pertinent to the traditional scheme of insight knowledges, simply because these two descriptions of the progress of insight are poles apart. The "Ingram model," if it can be called such, and the Theravāda scheme of insight knowledges are substantially different. What holds for the one does not hold for the other. Each of these two maps of meditation practice needs to be evaluated on its own terms, in order to avoid the type of confusion that results from conflating them.

Assertions made by Daniel Ingram, based on his personal model, are not relevant to an evaluation of the implications of the actual Theravāda insight knowledges experienced in intensive meditation, nor do they carry weight in relation to contemporary mindfulness-based practices.

\section{Claims to Awakening}

In line with a radical reinterpretation of the insight knowledges, a similar and perhaps even more radical reinterpretation appears to have taken place in relation to the stages of awakening. In fact, the claim to having reached the highest possible level of awakening recognized in early and Theravāda Buddhism occurs on the cover of the book by Ingram (2008/2018), which introduces the author as "the arahant Daniel M. Ingram."

Note that this employs the Pāli term "arahant" and thereby lays claim to having reached the acme of spiritual perfection as understood in the Theravāda tradition, which employs Pāli as its doctrinal and religious language. As explained by Gombrich (1988, p. 3), "hallmarks of Theravāda Buddhism are the use of Pali as its main sacred language and dependence on the Pali version of the Buddhist Canon as its sacred scripture." Due to the employment of Pāli terminology, the claim made by Daniel Ingram is firmly situated within the Theravāda context and needs to be evaluated from the viewpoint of the Theravāda definition of what makes someone an arahant. Other Buddhist traditions are not of relevance for evaluating his claim. For example, the usage of the Sanskrit counterpart arhat in the context of descriptions in other Buddhist traditions of the non-bodhisattva or non-Mahāyāna path and the respective (often polemical) taxonomies of the paths and stages of awakening is neither text-historically nor doctrinally comparable to Ingram's procedure and does not represent a precedent to it.

From the stage of early Buddhism, represented by the Pāli discourses (and their parallels), to later Pāli texts, the notion that an arahant has eradicated defilements is a continuous key element in Theravāda thought. This holds even for the Bāhiya instruction, which Ingram (2008/2018, p. 320) apparently considers to be reflecting an alternative model of awakening. This idea seems to be based on the assumption that in the relevant Pāli discourse the Buddha "said that realization involves this direct insight: 'In the seeing just the seen, in the hearing just the heard, in the sensed just the sensed, in the cognized just the cognized." In the Pāli original, the phrase just quoted is an instruction for meditative training, evident from the fact that it is preceded by the phrase "Bāhiya, you should train yourself thus" (Ud 1.10: te bāhiya evam sikkhitabbam ). This is thus a meditation instruction in bare awareness (Anālayo 2018a, 2019a). Even though Bāhiya reached awakening after putting into practice this instruction, this does not turn the instruction itself into a description of a level of awakening. The ability to cultivate bare awareness as such does not imply that the practitioner must be an awakened being.

Ingram (2008/2018, p. 335) introduced his revised version of the four stages of awakening by reasoning that "using the original terminology and revising its definitions allows a lot of the most universally applicable and least culturally conditioned information from the Pāli canon to be used today." Regarding the idea of altering the implications of key constructs in order to make them more universally applicable, suppose the same procedure were to be applied in the medical professions. Someone could claim to be a medical doctor without ever having studied or practiced medicine, a contention justified so as to make personal attempts at contributing to healthcare more universally applicable than they would be without such claims. The results of such a procedure can safely be expected to be detrimental. The same holds for claims to Buddhist levels of 
awakening based on a personal revision of the definition of what awakening implies.

In view of the position taken in the Theravāda tradition on the implications of being an arahant, the appropriation of the Pāli term arahant by someone who is still subject to defilements like sexual lust and anger risks being considered a case of wrongful cultural appropriation. In the present instance, a white male from a dominant Western culture employs a term with profound sacred connotations among Theravāda populations of South and Southeast Asia who have inherited a history, especially on being subjected to colonial rule, of pervasive oppression of their religious culture by Western powers. The appropriation of this term takes place in full awareness of not doing justice, by any means, to the connotations it evokes in its traditional usage, where the mere mention of the Pāli term arahant can move people to tears and motivate them to engage in various traditional forms of expressing respect. Such respect is motivated precisely by the chief connotation of total liberation from defilements. Hence, for someone to appropriate the term arahant without living up to this connotation can be experienced as deeply offensive by those among such Theravāda populations (including immigrants living in the West) who come to know of it.

Although the vocabulary of cultural appropriation was of course not known in ancient India, the seriousness of making claims to being an arahant in awareness of failing to fulfil the relevant chief criteria can be seen in the following Pāli verse:

Someone who, not being an arahant, claims to be an arahant, in this world with its gods is a thief.

(Sn 135: yo ve anarahā santo, araham patijānati, coro sabrahmake loke).

Yet, Ingram (2008/2018, p. 332) much rather targets the Buddhist tradition as being collectively reprehensible on ethical grounds for making the supposedly false claim that eradication of defilements is at all possible. This strategy, perhaps serving as a pre-emptive attack, takes the form of alleging that the entire Buddhist tradition, from its earliest stages onward, has been dishonest in claiming that it is possible to eradicate defilements from the mind, as implicit in the core meaning and implication of becoming an arahant. The alleged dishonesty was supposedly a move "to fool ignorant peasants" and get food supplies. Key elements of the arahant ideal in Pāli texts, according to which one who has reached this acme of perfection no longer has sex, kills, steals, etc., should therefore be viewed as "absurd lies" (p. 356).

\section{Insight Meditation}

The reinterpretation of the insight knowledges and stages of awakening comes combined with a significant change in the actual meditation method. The noting technique employed in the tradition of Mahāsi Sayādaw can be understood to put into practice an aspect of the instructions in the Satipatthāna-sutta, which "suggest a form of mental noting" (Anālayo 2003, p. 113). If used appropriately as an aid in clarity of recognition and understanding, such practice can lead to progress through the insight knowledges and the gaining of "levels of awakening" (Anālayo 2018b, p. 197). If overdone, however, in particular by employing a highspeed form of noting combined with excessive reliance on the expectation of certain experiences to be reached, the crucial receptivity of mindfulness can become lost, and the employment of the noting technique can result in scripting meditation experiences to conform to the practitioner's personal ideas and expectations (Anālayo 2020a).

Needless to say, Daniel Ingram is of course free to adjust the meditation technique taught by Mahāsi Sayādaw as he wishes for his personal practice, such as adopting high-speed noting as a tool for actualizing his own map. In fact, his approach appears to have attracted a number of meditators who are comfortable relying on the same mode of practice and on his map as the chief reference point for their practice.

However, the purpose of the present article, as would be evident from its submission to an academic journal, is to provide information to scholars in the field of psychology. In particular, those involved in research on mindfulness-based clinical applications and programs need to be provided with information to contextualize the claims made by Daniel Ingram of being an authorized insight meditation teacher who has reached the highest goal envisaged in early and Theravāda Buddhism.

In an invited comment on the presentation in Anālayo (2020a), Bhikkhu Vivekānanda Mahāthera, an internationally renowned insight meditation teacher in the tradition of Mahāsi Sayādaw, clarified (Vivekānanda 2020):

Mr. Daniel Ingram's teachings of meditation do not accord with Ven. Mahasi Sayadaw's teachings of Vipassana meditation ... Mr. Daniel Ingram's way of teaching meditation is actually causing harm to a number of his students.

Kornfield (2020) also warned that "the approach of a heavy, forced and intense effort to note every experience can further exacerbate adverse reactions." In the same vein, Kirmayer (2015, p. 463 n. 9) noted that.

recent 'hardcore' (Ingram 2008) approaches to meditative practice ... as a way to advance along the path to enlightenment may be particularly stressful and put some individuals at risk for meditation-related pathologies.

These comments point to the potentially harmful consequences of commending an unbalanced form of practice under the overarching drive to conform to a self-made map 
of the progress of insight. Yet, perhaps in another pre-emptive attack in line with the apparent mode of defense adopted for the claim to being an arahant, Ingram (2008/2018, p. 296) alleged that problems during insight meditation arise because meditators are intentionally kept ignorant of the insight knowledges, the teachers of insight meditation being part of a "warped culture of secrecy."

Information on the genuine insight knowledges has long been publicly available (Anālayo 2020a). Potential problems arising from intensive insight meditation in a retreat setting were studied soon after such form of meditation was introduced in the West. Kornfield (1979, p. 44) provided a detailed survey of "unusual experiences," reported by insight meditators, so as to enable Western psychologists to assess such phenomena appropriately from the viewpoint of their potentially pathological nature. Right away on the first page of another relevant publication, Epstein and Lieff (1981, p. 137) highlighted the need for clarifications regarding "the range of side effects of meditative practices that may present to the clinician as psychological disturbance" (for related studies published recently, see Lindahl et al. 2017, 2020).

Although research aimed at providing publicly available information on possible repercussions of insight meditation has thus a long history, the above argumentative strategy by Daniel Ingram, in combination with his misguided idea that the stages of insight can be experienced in daily life, appears to have been successful in raising ethical concerns among those researching general mindfulness practices. This has led to expressions of concern that merely teaching mindfulness in a clinical context could be fraught with danger.

The assumption that mindfulness is intrinsically dangerous, apparently to a considerable degree the result of Daniel Ingram's authentication strategies, is best considered a myth. As pointed out by Jack Kornfield (2020): "It is only the mistaken belief that the Progress of Insight stages are commonplace that can lead to sounding a false alarm that because of this, mindfulness itself may be dangerous."

\section{The End of the Myth?}

It should probably be considered a positive sign that authors like Barford (2018), Compson (2018), and Grabovac (2015) have been so ready to take up the alleged dangers of mindfulness, reflecting a high sensitivity in the field for potential ethical problems. This unfortunately combines with a lack of insight (pun intended) regarding the imaginary nature of the claims made by Daniel Ingram and the authentication strategy that stands behind his calls for research to be based on his self-made model. The main problem remains that scholars in the field of psychology are often not sufficiently well equipped with knowledge of Buddhist doctrine and Buddhist meditation traditions to be able to separate wheat from the chaff, in the sense of avoiding being misled by unfounded claims and the subjective imagination of a self-styled teacher.

The problem of imagination impacting memory is of course well known. Research by Goff and Roediger (1998, p. 28), for example, showed that "imagining actions led subjects to remember that they had actually performed the actions when in fact they had not." This "effect increased with the number of imaginings, as did subjects' confidence about their erroneous responses." Such imagination can easily lead to self-deception. As noted by Chance et al. (2015, p. 2), "the surest way to deceive others and not display signs of lying is to deceive oneself."

In the present case, the tendency to construct experience to confirm subjective expectations appears to have gone beyond the realm of meditative experiences. An example is the claim by Ingram (2008/2018, p. 433): "I have been authorized and encouraged to teach by a legitimate lineage," apparently made in the belief that Sayādaw U Pandita Jr. had conferred such authorization. Yet, according to Bhikkhu Vivekānanda (2020): "Neither Ven. Sayadaw U Pandita Jr. nor Ven. Sayadaw U Panditabhivamsa Sr. of Myanmar have ever authorized Mr. Daniel Ingram to teach meditation in the Mahasi tradition."

Another example is the report by Ingram (2008/2018, p. 476) that the renowned insight meditation teacher Joseph Goldstein gave him the following advice: "Nail down what you've got." Yet, those familiar with Joseph Goldstein's way of teaching will recognize that this type of expression does not fit his style. Joseph Goldstein (personal communication, October 9, 2020), confirmed that, even though he does not remember the actual encounter with Daniel Ingram, he is confident that he would not have given such advice, simply because this is not how he guides meditation practitioners. Thus, Daniel Ingram's wish for authentication appears to have led to distorted memories. All of this points to a loss of grounding in reality due to being carried away by imagination, be this related to meditation experiences, their implications, or even just ordinary communications. Such lack of grounding in reality, evident in the above-discussed reinterpretations and authentication strategies, is not a promising foundation for becoming involved in scientific research.

In sum, then, the alleged dangers of mindfulness appear to be a myth just as much as the criticism made under the heading of McMindfulness. Practicing mindfulness does not on its own result in becoming a mindless robot obedient to the dictates of neoliberal capitalism, nor does it clandestinely implant the germs of serious mental insanity. Instead, practicing mindfulness has a remarkable potential for increasing mental clarity and resilience. 
Abbreviations Sn: Sutta-nipāta; Ud: Udāna

Funding Open Access funding enabled and organized by Projekt DEAL.

\section{Declarations}

Ethics Approval This article does not contain any studies performed by the author with human participants or animals.

Conflict of Interest The author declares no competing interests.

Open Access This article is licensed under a Creative Commons Attribution 4.0 International License, which permits use, sharing, adaptation, distribution and reproduction in any medium or format, as long as you give appropriate credit to the original author(s) and the source, provide a link to the Creative Commons licence, and indicate if changes were made. The images or other third party material in this article are included in the article's Creative Commons licence, unless indicated otherwise in a credit line to the material. If material is not included in the article's Creative Commons licence and your intended use is not permitted by statutory regulation or exceeds the permitted use, you will need to obtain permission directly from the copyright holder. To view a copy of this licence, visit http://creativecommons.org/licenses/by/4.0/.

\section{References}

Anālayo, Bh. (2003). Satipatthāna, the direct path to realization. Windhorse Publications.

Anālayo, Bh. (2012). The dynamics of Theravāda insight meditation. In K. Chuang (Ed.), 佛教禪坐傳統國際學術砶討 會論文集 [Buddhist meditation traditions: an international symposium] (pp. 23-56). Dharma Drum Publishing Corporation.

Anālayo, Bh. (2018a). The Bāhiya instruction and bare awareness. Indian International Journal of Buddhist Studies, 19, 1-19.

Anālayo, Bh. (2018b). Satipaț̣̂hāna meditation: A practice guide. Cambridge: Windhorse Publications.

Anālayo, Bh. (2019a). In the seen just the seen: Mindfulness and the construction of experience. Mindfulness, 10(1), 179-184. https:// doi.org/10.1007/s12671-018-1042-9

Anālayo, Bh. (2019b). The insight knowledge of fear and adverse effects of mindfulness practices. Mindfulness, 10(10), 2172-2185. https://doi.org/10.1007/s12671-019-01198-4

Anālayo, Bh. (2020a). Meditation maps, attainment claims, and the adversities of mindfulness. Mindfulness, 11(9), 2102-2112. https://doi.org/10.1007/s12671-020-01389-4

Anālayo, Bh. (2020b). The Myth of McMindfulness. Mindfulness, 11(2), 472-479. https://doi.org/10.1007/s12671-019-01264-x

Baer, R., Crane, C., Miller, E., \& Kuyken, W. (2019). Doing no harm in mindfulness-based programs: Conceptual issues and empirical findings. Clinical Psychology Review, 71, 101-114. https://doi. org/10.1016/j.cpr.2019.01.001

Baer, R., Crane, C., Montero-Marin, J., Phillips, A., Taylor, L., Tickell, A., \& Kuyken, W. (2021). Frequency of self-reported unpleasant events and harm in a mindfulness-based program in two general population samples. Mindfulness, 12(3), 763-774. https://doi.org/ $10.1007 / \mathrm{s} 12671-020-01547-8$

Barford, D. (2018). Dark night of the soul: Duncan Barford explains why mindfulness is associated with risk of severe negative psychological effects. Therapy Today, 29(6), 34-37.
Chance, Z., Gino, F., Norton, M. I., \& Ariely, D. (2015). The slow decay and quick revival of self-deception. Frontiers in Psychology, 6(1075), 1-6. https://doi.org/10.3389/fpsyg.2015.01075

Compson, J. (2018). Adverse meditation experiences: Navigating Buddhist and secular frameworks for addressing them. Mindfulness, 9, 1358-1369. https://doi.org/10.1007/s12671-017-0878-8

Epstein, M., \& Lieff, J. D. (1981). Psychiatric complications of meditation practice. The Journal of Transpersonal Psychology, 13(2), 137-147.

Goff, L. M., \& Roediger, H. L. (1998). Imagination inflation for action events: Repeated imaginings lead to illusory recollections. Memory \& Cognition, 26(1), 20-33.

Gombrich, R. F. (1988). Theravāda Buddhism, a social history from ancient Benares to modern Colombo. London: Routledge \& Kegan Paul.

Grabovac, A. (2015). The stages of insight: Clinical relevance for mindfulness-based interventions. Mindfulness, 6, 589-600. https://doi.org/10.1007/s12671-014-0294-2

Ingram, D. M. (2008/2018). Mastering the core teachings of the Buddha: an unusually hardcore Dharma book, revised and expanded edition. London: Aeon.

Kirmayer, L. J. (2015). Mindfulness in cultural context. Transcultural Psychiatry, 52(4), 447-469. https://doi.org/10.1177/1363461515 598949

Kornfield, J. (1979). Intensive insight meditation: A phenomenological study. The Journal of Transpersonal Psychology, 11(1), 41-58.

Kornfield, J. (2020). Letter of November 29, 2020. http://agamaresea rch.dila.edu.tw/wp-content/uploads/2021/04/letterK.pdf

Lindahl, J. R., Fisher, N. E., Cooper, D. J., Rosen, R. K., \& Britton, W. B. (2017). The varieties of contemplative experience: A mixedmethods study of meditation-related challenges in Western Buddhists. PLoS One, 12(5), E0176239. https://doi.org/10.1371/journ al.pone. 0176239

Lindahl, J. R., Cooper, D. J., Fisher, N. E., Kirmayer, L. J., \& Britton, W. B. (2020). Progress or pathology? Differential diagnosis and intervention criteria for meditation-related challenges: Perspectives from Buddhist meditation teachers and practitioners. Frontiers in Psychology, 11(1905), 1-18. https://doi.org/10.3389/ fpsyg.2020.01905

Nānamomoli, Bh. (1991). The path of purification (Visuddhimagga) by Bhadantācariya Buddhaghosa. Kandy: Buddhist Publication Society.

Purser, R. E. (2019). McMindfulness, how mindfulness became the new capitalist spirituality. London: Repeater Books.

Treleaven, D. A. (2018). Trauma-sensitive mindfulness, practices for safe and transformative healing. New York: W. W. Norton \& Company.

Van Dam, N. T., van Vugt, M. K., Vago, D. R., Schmalzl, L., Saron, C. D., Olendzki, A., Meissner, T., Lazar, S. W., Kerr, C. E., Gorchov, J., Fox, K. C. R., Field, B. A., Britton, W. B., Brefczynski-Lewis, J. A., \& Meyer, D. E. (2018). Mind the hype: A critical evaluation and prescriptive agenda for research on mindfulness and meditation. Perspectives on Psychological Science, 13(1), 36-61. https:// doi.org/10.1177/1745691617709589

Vivekānanda, Bh. (2020). Letter of September 1, 2020. http://agama research.dila.edu.tw/wp-content/uploads/2021/04/letterV.pdf

Vörös, S. (2016). Sitting with the demons-mindfulness, suffering, and existential transformation. Asian Studies, 4(2), 59-83. https://doi. org/10.4312/as.2016.4.2.59-83

Publisher's Note Springer Nature remains neutral with regard to jurisdictional claims in published maps and institutional affiliations. 